\title{
CARACTERIZAÇÃO BIOQỨMICA DE CULTIVARES DE CANA-DE-AÇUUCAR (Saccharum spp.): ISOENZIMAS, PROTEÍNA SOLÚVEL E VALOR BRIX
}

\author{
M. DE ALMEIDA \\ Departamento de Botanica-USP/ESALQ, C.P. 9, CEP: 13418-900 - Piracicaba,SP \\ O.J. CROCOMO \\ CEBTEC e Departamento de Qutmica-ESALQ/USP, C.P. 9, CEP: 13418-900 - Piracicaba,SP
}

\begin{abstract}
RDSUMO: No presente trabalho foram determinados o perfil isoenximatico diferencial de esterase e peroxidase, a protefna total solível e os s6lidos solúveis (sacarose) em graus brix, de 10 cultivares de cana-de-açúcar (Saccharum spp.) atualmente cultivados no Brasil. Os cultivares estudados foram: NA 56-79, IAC 52-150, IAC 64-257, SP 701143, SP 71-3146, SP 71-3149, SP 71-1406, SP 71-6163, SP 71-61-68 e SP 71-799. Com os dados obtidos foi possivel com-provar o valor taxonômico das características bioquímicas que representam uma inovaçāo em taxonomia de cana-de-açúcar no Brasil. As isoenximas de esterase apresentaram um padrāo eletrofortico especifico para cada cultivar estudado, enquanto que as isoenximas de peroxidase so permitiram agrupar os cultivares por apresentarem o mesmo padrão eletrofortetico para cada grupo formado. Tanto as isoenrimas de esterase como peroxidase apresentaram-se constantes em um mesmo cultivar. Os solidos solúveis (sacarose) em Graus Brix e a determinação da proteína solúvel, mesmo sendo pouco variáveis, apresentaram-se úteis para a caracterizaçåo dos cultivares estudados. Descritores: quimiotaxonomia, cana-de-açicar, isoenzimas, esterase, peroxidase
\end{abstract}

\section{BIOCHEMICAL CHARACTERIZATION OR SUGARCANR (Sacchenum spp.) CULTIVARS: ISOENZYMES, SOLUBLE PROTEIN AND BRIX VALUE}

\begin{abstract}
In the present work the isoenzyme profiles of the enzymes esterase and peroxidase, the level of total soluble protein and the soluble solids (sucrose) were determined of the following sugarcane (Saccharum spp.) cultivars: NA 56-79; IAC 52-150; IAC 64-257; SP 70-1143; SP 71-3146; SP 71-3149; SP 71-1406; SP 71-6163; SP 7161-68 and SP 71-799. Esterase isoenzymes showed a specific electrophoretic pattern for each one of the cultivars, while the peroxidase allowed to arrange the cultivars in groups, each one with a specific electrophoretic pattern. The isoenzymes of both esterase and peroxidase were constant in a given cultivar. Total soluble protein levels and soluble solids (sucrose, Brix value) varied among the cultivars. Statistical analysis showed that these biochemical parameters are useful for the characterization of the cultivars under study.
\end{abstract}

Key Words: chemotaxonomy, sugarcane, isoenzymes, esterase, peroxidase

\section{INTRODUÇÃO}

A procura de híbridos resistentes e mais produtivos em cana-de-açúcar (Saccharum spp.), levou ao aparecimento de centenas de novos cultivares, causando uma crescente dificuldade na identificação dos mesmos, que nem sempre, com os métodos tradicionais de observações morfológicas, podiam ser reconhecidos.

LARSEM (1969) estabeleceu que todas as manifestações morfológicas inerentes de diferenças vegetais devem ultimamente, ter uma diferença bioquímica, mas nem todas essas diferenças são necessariamente refletidas morfologicamente. Assim as diferenças bioquímicas deverão ser mais numerosas do que as morfologicas.
Revela-se desse modo a importância de um método bioquímico aplicado à sistemática vegetal. Nesse sentido o pioneiro foi BOULTER et al. (1967) que, analisando as globulinas de sementes de leguminosas através da eletroforese de disco, caracterizaram doze tribos desta ordem, subdividindo as espécies estudadas dentro de cada grupo.

DERBYSHIRE et al. (1976), basearam-se nos padrões eletroforéticos das globulinas de sementes de espéceis de Phaseolus e classificaram em grupos as espécies deste gênero. Com os mesmos objetivos destacam-se os trabalhos de JOHNSON (1967, 1972), JOHNSON \& HALL (1966), JOHNSON et al. (1967) e JOHNSON e THEIN (1970). 
- termo isoenzimas foi primeiro introduzido por MARKET \& MOLLER (1959) para referir-se as múltiplas formas de uma enzima, com especificidade similar ou idêntica por um substrato, ocorrendo dentro do mesmo organismo.

A preferência pór isoenzimas, súbstituindo as manifestações fenotípicas de características das plantas de cada cultivar está bem situada (BASSIRI \& ROUHÁNI, 1977). Isto, segundo diversos autores é decorrência da obtenção de padrões altamente repetitivos, desde que as isoenzimas são expressões quase que exclusivas da carga genética do cultivar e deste modo, não afetadas pelas condições ambientais (SCHWARTZ, 1960; LOESCHCKE \& STEGAMANN, 1966; LEE \& RONALDS, 1967; LARSEN, 1969). Entretanto a necessidade das isoenzimas dos diversos tecidos vegetais submetidos a condiçôes ambientais distintas, é variável. De JONG et al. (1968) mostraram variações qualiquantitativas em isoenzimas de células de tabaco, cultivadas em suspensão sob diferentes temperaturas. THOM \& MARETZKI (1970) informaram que a idade e o estresse fisiológico podem causar manifestações em isoenzimas por afetar a estabilidade da informação genética. McCOWN et al. (1969) encontraram diferenças nas isoenzimas componentes da fosfatase ácida e esterase em Dianthus sob condições de inverno e verão.

Assim que uma planta cresce e o desenvolvimento ocorre, as variações isoenzimáticas qualitativas são frequentemente dramáticas $e$ incluem $o$ aparecimeno de novas bandas e o desaparecimento de outras (PIERCE \& BREWBAKER, 1973). THURMAN et al. (1965) verificaram que a atividade de sete bandas, presentes em uma semente madura, decresce de atividade durante a germinação e vinte um dias após detecta-se uma banda; SIEGEL \& GALSTON (1967) observaram diferenças isoenzimáticas quantitativas durante o desenvolvimento de ervilha; BHATIA \& NILSON (1969) verificaram diferenças qualiquantitativas nos padrões de esterase e peroxidase durante a germinação de sementes de trigo. MACKO et al. (1967), também estudando trigo durante a germinação e o crescimento demonstraram variações nos padrões de doze isoenzimas. STODDART (1971) demonstrou variações isozímicas em uma enzima, durante a maturação de sementes de aveia. JOHNSON et al. (1973) relataram variações de isoenzimas de fosfatase ácida durante a germinação de sementes de ervilha. KRASNOOK et al. (1979) mostraram haver uma correlação qualiquantitativa com o poder germinativo das sementes de arroz.

A maior vantagem do método de isoenzima neste contexto, $€$ que a maioria dos tecidos podem ser analisados. Cultivares de citros, banana, abacaxi, pluméria e cravo têm sido distinguidos isoenzimicamente pela amostra de tecidos que são morfologicamente indistinguíveis (PIERCE \& BREWBAKER, 1973). Isoenzimas de pólens identificam diferentes clones de abacaxi (BREWBAKER, 1971); clones altamente poliplóides de cana-de-açúcar são prontamente identificados por isoenzimas de folhas (HEINZ \& GRACE, 1969).

Em cana-de-açúcar, a identificação de cultivares tem sido feita usando as isoenzimas peroxidase e esterase (THOM \& MARETZKI, 1970); esterase, fosfatase ácida e leucilaminopeptidase (WALDRON \& GLASZIOU, 1972); sendo que, segundo CURY \& CROCOMO (1980), parece que nenhum trabalho $\varepsilon$ mencionado na literatura usando as isoenzimas desidrogenase alcoólica (ADH) ou desidrogenase málica (MDH) na identificação da cana-de-açúcar. Estes autores desenvolveram metodologia para a dosagem eletroforética em gel de poliacrilamida simultânea das isoenzimas de ADH e MDH.

GONÇALVES et al. (1981) propuseram que o melhor tecido para a análise de zimograma de cana-de-açúcar é a gema, e que o padrão eletroforético, no caso da esterase, se mantém em plantas de idades fisiológicas distintas, crescidas em ambiente controlado.

\section{MATERIAL E METTODOS}

Os trabalhos de observações morfologicas tiveram início em maio de 1984, quando foram utilizadas soqueiras em quatro ruas de cinquenta metros para cada cultivar, na Estação Copersucar em Piracicaba - SP.

Os seguintes dez cultivares de cana-deaçúcar: NA 56-79, IAC 52-150, IAC 64-257, SP 70-1143, SP 71-799, SP 71-1406, SP 71-3146, SP 71-3149, SP 71-6163, SP 71-6180 foram mantidos sob condições climáticas, edáficas e culturais, as mais uniformes possíveis, afastando desta maneira as variações causadas pelo meio.

\section{ANÁLISES BIOQUÍMICAS}

Coleta e preparo do material: foram extraídas as gemas correspondentes aos entre-nós de número 5 
a 10 , de 18 plantas de cada cultivar e conduzidas ao laboratório de Bioquímica de Plantas do CENA/USP, onde foram liofilizadas, moídas $e$ conservadas em câmara fria a uma temperatura de $10^{\circ} \mathrm{C}$

Proteína total solúvel: a) Extrações: As proteínas totais solúveis foram extraídas com tampão Tris $0,2 \mathrm{M} \mathrm{e} \mathrm{NaCl} \mathrm{0,05} \mathrm{M;} \mathrm{pH} 8.0$ (LEE, 1978) e com

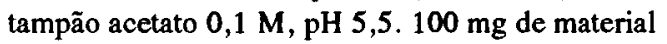
liofilizado das gemas de cada cultivar foram homogeinizadas com $2,0 \mathrm{ml}$ do tampão em almofariz, a $4^{\circ} \mathrm{C}$, durante um minuto. A suspensão foi centrifugada a $4^{\circ} \mathrm{C}$ por 30 minutos à $12000 \mathrm{xg}$; b) Dosagem: A proteína total solúvel foi determinada no sobrenadante obtido como descrito acima; utilizou-se o método de LOWRY et al. (1951), pH 5,5 e a pH 8,0.

Isoenzimas das gemas: As isoenzimas foram extraídas das gemas das diferentes cultivares, com o solvente e tampão acetato $0,1 \mathrm{M}, \mathrm{pH}$ 5,5 , utilizando a proporção de $100 \mathrm{mg}$ do material liofilizado das gemas, por $2 \mathrm{ml}$ do tampão, com a adição de uma gota de 2mercaptoetanol a $0,5 \%$.

Analise das proteínas: a) Separação eletroforética das proteínas não dissociadas: seguindo-se 0 método de DAVIS (1964), utilizou-se gel de poliacrilamida a $7 \%$ no gel de separação, com um comprimento de $5,5 \mathrm{~cm}$ e $0,5 \mathrm{~cm}$ de diâmetro. A eletroforese foi realizada a $4^{\circ} \mathrm{C}$, sob $1 \mathrm{~mA} / \mathrm{gel}$, até o fim da corrida; b) Análise das proteínas: extratos das gemas foram submetidos a separação eletroforética e o $\mathrm{pH}$ dos géis foram neutralizados nos tampões de incubação por $5 \mathrm{~min}$ e a seguir géis distintos em duplicatas foram incubados para a visualização da atividade das isoenzimas descritas a seguir:

Esterase: os géis foram incubados no escuro durante 20 minutos à $25^{\circ} \mathrm{C}$ em tampão fosfato 0,1 $\mathrm{M}$ a $\mathrm{pH}$ 6,0: contendo 0,5 $\mathrm{mg} / \mathrm{ml}$ de "Fast Blue RR" e $0,2 \mathrm{mg} / \mathrm{ml}$ de $\alpha$-naftilacetato. A seguir os géis foram fixados e descorados na mistura água + etanol + ácido acético (5:5:1).

Peroxidase: os géis foram incubados em ácido acético $10 \%$, contendo $0,5 \mathrm{mg} / \mathrm{ml}$ de O-dianisidina e $\mathrm{H}_{2} \mathrm{O}_{2}$ à $0,012 \mathrm{~V}$. Após 30 minutos no escuro e a $37^{\circ} \mathrm{C}$ paralisou-se a reação com ácido ascórbico $1 \%$ (NAGLE \& HAARD, 1975).
S6lidos solúveis (sacarose): em cada uma das dezoito repetições de cada cultivar foram determinados os sólidos solúveis (sacarose) pelo processo refratométrico, expressos em graus Brix; utilizou-se um Refratômetro Manual Modelo AO T/C.

\section{DELINEAMENTO ESTATISTICO}

O delineamento estatístico adotado para o caracter "sólidos solúveis (sacarose)" foi o inteiramente casualizado, constando de 10 tratamentos (10 cultivares) e 18 repetições. Para comparação das médias dos tratamentos foi utilizado o método de Tukey, ao nível de 5\%. Este dado está representado na TABELA 1.

TABELA 1 - Sólidos solúveis (sacarose) em graus Brix em cultivares de cana-de-açúcar.

\begin{tabular}{ll}
\hline \multicolumn{1}{c}{ Cultivares } & $\begin{array}{l}\text { Média das } \\
\text { repetições }\end{array}$ \\
\hline SP 71-6163 & $25,22 \mathrm{a}$ \\
NA 56-79 & $25,03 \mathrm{a}$ \\
SP 71-6180 & $24,89 \mathrm{ab}$ \\
SP 70-1143 & $24,86 \mathrm{ab}$ \\
IAC 52-150 & $24,06 \mathrm{abc}$ \\
SP 71-799 & $24,00 \mathrm{abc}$ \\
SP 71-3149 & $23,22 \mathrm{bcd}$ \\
SP 71-1406 & $22,72 \mathrm{~cd}$ \\
IAC 64-257 & $22,61 \mathrm{~cd}$ \\
SP 71-3146 & $22,06 \mathrm{~d}$ \\
\hline F (Trat.) & $9,03 * *$ \\
D.M.S. (5\%) & 1,71 \\
C.V. (\%) & 6,79 \\
\hline
\end{tabular}

** Significativo ao nível de $1 \%$ de probabilidade.

\section{RESULTADOS}

Os resultados obtidos permitiram que os cultivares fossem assim descritos:

\footnotetext{
SP 71-6163

Teor de sacarose (TABELA 1): 25, 22 graus Brix;

Zimograma das isoenzimas: esterásicas (Figura 1) e peroxidásicas (Figura 2);

Proteína total solúvel (Tabela 2): a pH 5,5 $10,04 \mathrm{mg} / 100 \mathrm{mg}$ de matéria seca e a $\mathrm{pH} 8,0$ $52,00 \mathrm{mg} / 100 \mathrm{mg}$ de matéria seca.
} 


\section{SP 71-3149}

Teor de sacarose (TABELA 1): 23,22 graus Brix; Zimograma das isoenzimas: esterásicas (Figura 1) e peroxidásicas (Figura 2);

Proteína total solúvel (TABELA 2): a pH 5,5$8,81 \mathrm{mg} / 100 \mathrm{mg}$ de matéria seca e a $\mathrm{pH} 8,0$ $43,25 \mathrm{mg} / 100 \mathrm{mg}$ de matéria seca.

IAC 64-257

Teor de sacarose (TABELA 1): 22,61 graus Brix; Zimograma das isoenzimas: esterásicas (Figura 1) e peroxidásicas (Figura 2);

Proteína total solúvel (TABELA 2): a pH 5,5$7,50 \mathrm{mg} / 100 \mathrm{mg}$ de matéria seca e a $\mathrm{pH} 8,0$ $39,00 \mathrm{mg} / 100 \mathrm{mg}$ de matéria seca.

\section{SP 71-799}

Teor de sacarose (TABELA 1): 24,00 graus Brix; Zimograma das isoenzimas: esterásicas (Figura 1) e peroxidásicas (Figura 2);

Proteína total solúvel (TABELA 2): a pH 5,5 $10,03 \mathrm{mg} / 100 \mathrm{mg}$ de matéria seca.

\section{SP 70-1143}

Teor de sacarose (TABELA 1): 24,86 graus Brix; Zimograma das isoenzimas: esterásicas (Figura 1) e peroxidásicas (Figura 2);

Proteína total solúvel (TABELA 2): a pH 5,5 $6,47 \mathrm{mg} / 100 \mathrm{mg}$ de matéria seca e a $\mathrm{pH} 8,0$ $34,50 \mathrm{mg} / 100 \mathrm{mg}$ de matéria seca.

\section{SP 71-3146}

Teor de sacarose (TABELA 1): 22,06 graus Brix; Zimograma das isoenzimas: esterásicas (Figura 1) e peroxidásicas (Figura 2);

Proteína total solúvel (TABELA 2): a pH 5,5$9,93 \mathrm{mg} / 100 \mathrm{mg}$ de matéria seca e a $\mathrm{pH} 8,0$ $47,65 \mathrm{mg} / 100 \mathrm{mg}$ de matéria seca.

\section{SP 71-6180}

Teor de sacarose (TABELA 1): 24,89 graus Brix; Zimograma das isoenzimas: esterásicas (Figura 1) e peroxidásicas (Figura 2);

Proteína total solúvel (TABELA 2): a pH 5,5 $9,92 \mathrm{mg} / 100 \mathrm{mg}$ de matéria seca e a $\mathrm{pH} 8,0$ $47,65 \mathrm{mg} / 100 \mathrm{mg}$ de matéria seca.

\section{SP 71-1406}

Teor de sacarose (TABELA 1): 22,72 graus Brix; Zimograma das isoenzimas: esterásicas (Figura 1) e peroxidásicas (Figura 2).

Proteína total solúvel (TABELA 2): a pH 5,5 $10,03 \mathrm{mg} / 100 \mathrm{mg}$ de matéria seca e a $\mathrm{pH} 8,0$ $52,00 \mathrm{mg} / 100 \mathrm{mg}$ de materia seca.

\section{IAC 51-150}

Teor de sacarose (TABELA 1): 24,06 graus Brix; Zimograma das isoenzimas: esterásicas (Figura 1) e peroxidásicas (Figura 2);

Proteína total solúvel (TABELA 2): a pH 5,5 $9,95 \mathrm{mg} / 100 \mathrm{mg}$ de matéria seca e a $\mathrm{pH} 8,0$ $47,65 \mathrm{mg} / 100 \mathrm{mg}$ de matéria seca.

TABELA 2 - Proteína total sislúvel (mg/100 mg M.S.) em cultivares de cana-deaçúcar.

\begin{tabular}{lcc}
\hline Variedade & pH 8,0 & pH 5,5 \\
\hline SP 70-1143 & 34,50 & 06,47 \\
SP 71-3146 & 47,65 & 09,93 \\
IAC 64-257 & 39,00 & 07,50 \\
SP 71-6163 & 52,00 & 10,04 \\
SP 71-6180 & 47,65 & 09,92 \\
SP 71-3149 & 43,25 & 08,81 \\
SP 71-1406 & 52,00 & 10,03 \\
SP 71-799 & 52,00 & 10,03 \\
NA 56-79 & 47,65 & 09,96 \\
IAC 52-150 & 47,65 & 09,95 \\
\hline
\end{tabular}

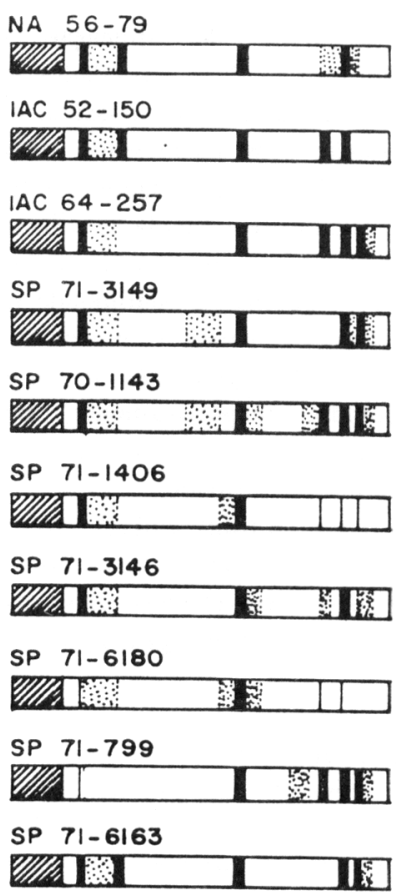

Figura 1 - Zimograma das isoenzimas de esterase dos cultivares de cana-de-açúcar. 


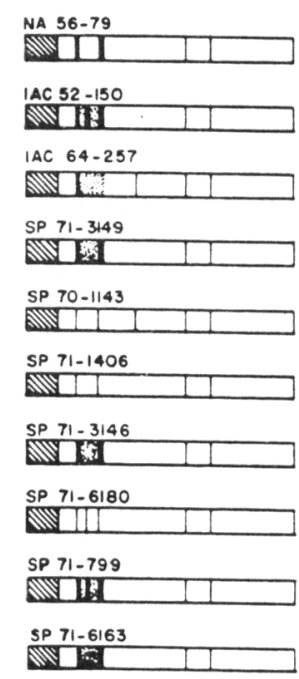

Figura 2 - Zimograma das isoenzimas de peroxidase dos cultivares de cana-de-açúcar.

\section{DISCUSSÃO}

Análise bioquímica - na apreciação das características bioquímicas, foi possível observar que os sólidos solúveis (sacarose) em graus Brix apresentaram grande importância principalmente por sua facilidade de aplicação e custo relativamente baixo. Para variedades cultivadas melhoradas geneticamente foi possivel notar uma pequena variação entre os mesmos, o que traz a necessidade de se obter dados extremamente precisos. Para tanto recomenda-se utilizar somente os entre-nós da região mediana do colmo por se tratar da região de maior estabilidade da planta, pois tanto os entre-nós mais velhos da base, como os mais jovens do ápice, são bioquimicamene instáveis devido, respectivamente, aos gastos energéticos necessários durante o processo de brotação e à sua imaturidade.

A proteína total solúvel, tanto a $\mathrm{pH} 5,5$ como a $\mathrm{pH} 8,0$, apresentou-se muito estável no cultivar e pouco variável entre eles, mas é uma característica que permite agrupar as variedades, em alguns casos, como 'SP-6163', 'SP-70-1143' e 'IAC 64-257'; cada cultivar apresentou um valor próprio que os distinguia dos demais.

Objetivando um projeto de seleção de cultivares deve-se levar em consideração o método de análise e qual o parâmetro de comparação.

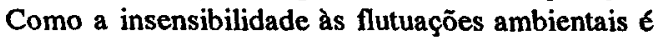
um fator essencial em qualquer programa de seleção, todo material coletado para as análises das isoenzimas dos 10 cultivares foram mantidos sob as mesmas condições como forma de padronizar as possíveis alterações causadas pelo ambiente.

Segundo GONÇALVES et al. (1981), a gema da cana-de-açúcar é o material mais recomendado para a determinação de isoenzimas por se tratar de uma estrutura mais estável e menos dependente do ambiente. Em uma planta adulta de cana-de-açúcar podem ser observados três estágios de gemas em um mesmo colmo, que são: gemas jovens e em formação, representadas pelas gemas do palmito até as de número três e quatro; gemas maduras e latentes, que se encontram na região mediana do colmo; e gemas em início de brotação, que geralmente se encontram na base da planta. Optou-se pelo uso das gemas maduras e latentes por já terem completado seu desenvolvimento, logo apresentam suas características morfológicas e bioquímicas manifestadas e, por estarem latentes, haverá uma estabilidade enzimática relativamente alta para todos os cultivares examinados, pois as expressões das isoenzimas dos diversos tecidos vegetais pode ser alterada pelo ambiente (DeJONG et al., 1968; THOM \& MARETZKI, $1970 \mathrm{e}$ McCOWN et al., 1969).

Por estas razões a gema da cana-deaçúcar é um instrumento mais valioso na determinação de cultivares que os demais caracteres vegetativos, onde as alterações ontogênicas, geralmente induzidas pelo ambiene nos padrões isoenzimáticos, podem transcender a variabilidade interespecífica (HART \& BHATIA, 1967; KELLEY \& ADAMS, 1977).

De acordo com LOOMIS (1974), tecidos vegetais apresentam problemas especiais para $o$ isolamento de enzimas, devido à presença de uma grande variedade de produtos secundários e de fenol oxidase. Apesar de até o momento não existir métodos gerais aplicáveis para isolar enzimas de vegetais, o presente trabalho levou em consideração estes fatores e durante o procedimento de extração procurou-se minimizá-los. Assim sendo, utilizou-se baixa temperatura e um tempo mínimo necessário de extração para superar principalmente o problema de proteólise, a qual poderia, pela degradação parcial das proteínas, originar artifícios no perfil das isoenzimas. Sendo ainda relevante o fato de que a porcentagem de proteínas extraídas durante um minuto em almofariz é a mesma que TSENSHENG (1970) extraiu em trinta minutos de agitação em câmara fria.

Agentes antioxidantes sulfidricos foram utilizados para impedir a polimerização das proteí- 
nas que poderiam inibir totalmente as enzimas, bem como reduzir sua atividade, produzindo faixas artificiais (CURY, 1980). Ainda segundo CURY \& CROCOMO (1980), o uso de tampão acetato $0,1 \mathrm{M}$ a pH 5,5 com a adição de 2-mercaptoetanol a $0,5 \%$, mostrou ser o melhor extrator de isoenzimas de tecido de gema de cana-de-açúcar.

Hoje está bem documentado que, assim que uma diferenciação celular progride levando a um desenvolvimento morfológico e uma especialização funcional, há uma contínua síntese e/ou degradação de enzimas específicas e proteínas estruturais. Um fator comum em desenvolvimento e diferenciação celular é a habilidade das células em perder ou adquirir características bioquímicas específicas.

Duas das principais alterações encontradas na maioria dos organismos são as variações quantitativas $e$ qualitativas na atividade enzimática dentro de suas células. $O$ aparecimento de uma nova atividade enzimática ou seu aumento no organismo em desenvolvimento, pode ser o resultado da síntese de nova molécula enzimática, ou a ativação de um precursor pré-existente da enzima (SCANDALIOS, 1974).

Assim que uma planta cresce e o desenvolvimento ocorre, as variações isoenzimáticas qualitativas são frequentemente dramáticas $\mathrm{e}$ incluem o aparecimento de novas faixas e o desaparecimento de cutras (PIERCE \& BREWBAKER, 1973). Diferenças qualiquantitativas foram observadas e comprovadas por diversos autores em diferentes plantas e órgãos (THURMAN et al., 1965; SIEGEL \& GALSTON, 1967; BHATIA \& NILSON, 1969; STODDART, 1971; JOHNSON et al., 1973 e KRASNOOK et al., 1979).

SHANNON (1968) comprovou que, quando células de diferentes órgãos são crescidas em cultura in vitro $\mathrm{e}$ expostas a idênticas condições, elas desenvolvem um padrão enzimático uniforme. Assim sendo, o meio citoplasmático deve controlar uma atividade diferencial dos genes e deste modo regular os padrões isoenzimáticos específicos dos tecidos. Ainda SHANNON (1968) demonstrou que em plantas, o padrão isoenzimático pode ser influenciado pela presença ou ausência de fitorreguladores, como ácido giberélico, ácido indolacético e cinetina.

OCKERSE et al. (1966), demonstraram que uma isoenzima de peroxidase do caule é reprimida pelo ácido indolacético e GALSTON (1967), relatou que o ácido indolacético pode alterar o nível de várias peroxidases.
Todos estes fatos, como alterações qualiquantitativas das isoenzimas produzidas pelo desenvolvimento e diferenciação, como pela ação de fitorreguladores, também justificam o uso da gema de cana-de-açúcar em estágio de dormência, como sendo a melhor estrutura na análise de isoenzimas na determinação de cultivares.

Isoenzimas de diversos sistemas enzimáticos poderiam ter sido utilizados na determinação dos dez cultivares examinados, mas segundo THOM \& MARETZKI (1970), os modelos de isoenzimas de esterase e peroxidase em um mesmo tecido de cana-de-açúcar, são específicos para cada clone, diferindo qualitativa e quantitativamente um do outro, com poucas exceções. Segundo BARRETO \& SIMON (1982), 19 variedades de cana-de-açúcar foram diferenciadas pelos zimogramas de peroxidase e esterase, devido a variação intervarietal existente, de maneira a ser recomendado seu uso na determinação de variedades em cana-de-açúcar.

GONÇALVES et al. (1981) observaram que o padrão eletroforético, no caso das isoenzimas de esterase, se mantém em plantas com idades fisiologicas distintas, desde que crescidas em ambiente controlado. Com base nestes autores é que foram utilizadas no presente trabalho as isoenzimas de esterase e peroxidase como parâmetro de diferenciação dos 10 cultivares estudados.

Com relação às isoenzimas de esterase (Figura 1), pode-se observar um comportamento específico nos zimogramas de cada cultivar, sendo que as faixas, a contar pela origem, de número 3 , $4,5,7,8,9,10,11$ e 13 , não foram constantes nos cultivares e somente a faixa de número 6 esteve presente e com a mesma intensidade em todos, mostrando ser provavelmente uma faixa comum à espécie, enquanto que as faixas de número 1,2 e 12 , apesar de sempre estarem presentes, apresentam-se com diferentes intensidades entre os cultivares.

Para as isoenzimas de peroxidase (Figura 2), obteve-se menor número de faixas do que com esterase, os quais também foram menos variáveis entre os cultivares, existindo padrões eletroforéticos idênticos que permitiram agrupar alguns dos cultivares, tais como: IAC 52-150 e SP 71-799 e também SP 71-3146; SP 71-3149 e SP 71-6163, por apresentarem padrões isoenzimáticos semelhantes em cada um dos agrupamentos. Nos demais cultivares, apesar de apresentarem zimogramas específicos, notou-se que as diferenças entre eles foram muito poucas pois 'NA 56-79' 
apresentou-se diferente do agrupamento com 'SP 71-3149' e 'SP 71-6163', por não apresentar a faixa delgada que ocorre entre a primeira e a segunda faixa intensa. Já os cultivares SP 70-1143 e SP 71-6180 são distintos de SP 71-1406, por uma faixa, ou seja, 'SP 70-1143' apresenta a terceira faixa a partir da origem, o que não ocorre em 'SP 71-1406'. O cultivar SP 71-6180 apresenta uma faixa extra, o que não ocorre entre as duas primeiras de 'SP71-1406'. Somente o IAC 64-257 apresentou um zimograma característico e mais distinto para as isoenzimas de peroxidase que os demais cultivares.

\section{CONCLUSÕES}

1) Com os dados obtidos foi possível comprovar o valor taxonômico das características bioquímicas;

2) As isoenzimas de peroxidase apresentam um valor taxonômico menos específico que as de esterase, uma vez que só permitem agrupar os cultivares;

3) As isoenzimas de esterase apresentam um padrão eletroforético específico para cada cultivar estudado;

4) Tanto as isoenzimas de esterase como as de peroxidase apresentam-se constantes para um mesmo cultivar;

5) Os sólidos solúveis (sacarose) em Graus Brix e a determinação da proteina total solúvel apresentaram um pequeno valor para a caracterização dos cultivares.

\section{REFERÊNCIAS BIBLIOGRÁFICAS}

BARRETO, A.; SIMON, J.P. Identificação de progenies y progenitores por el analisis del numero cromossomico em Saccharum. Turrialba, San Jose, v.32, n.3, p.321-327, 1982.

BASSIRI, A.; ROUHANI, I. Identification of broad bean cultivars based on isozimes patterns. Euphytica, Wageningen, v.26, p.279-286, 1977.

BHATIA, C.R.; NILSON, J.P. Isozyme changes accopanying germination of wheat seeds. Biochemical Genetics, New York, v.3, p.207-214, 1969.

BOULTER, D.; THURMAN, D.A.; DERBYSHIRE, E. A disc eletrophoretic study of globulin proteins of legume seeds with reference to their systematics. New Phytologist, London, v.66, p.27-36, 1967.
BREWBAKER, J.L. Pollen enzymes and isoenzymes. In: Polen: development and physiology. London: Butterworth, 1971. p.156-170.

CURY, J.A. Contribuição ao estudo das isoenzimas de sementes de feijão (Phaseolus vulgaris L.). São Paulo, 1980. 124p. Tese (Doutorado) Instituto de Química, Universidade de São Paulo.

CURY, J.A.; CROCOMO, O.J. Determinação simultânea de desidrogenase alcoólica (ADH) e desidrogenase málica (MDH) em cana-de-açúcar (Saccharum spp.). Energia Nuclear e Agricultura, Piracicaba, v.2, n.1, p.74-77, 1980.

DAVIS, B.J. Disc electrophoresis. II. Method and application to human serum proteins. Annales of the New York Academy of Science, New York, v.121, p.407-427, 1964.

DeJONG, D.W.; OLSON, A.C.; HAWKER, K.M.; JANSEN, E.F. Effect of cultivation temperature on peroxidase isoenzymes of plant cells grown in suspension. Plant Physiology, Rockville, v.43, p.841-844, 1968 .

DERBYSHIRE, E.; WRIGHT, D.J.; BOULTER, D. Review: Legumin and vicilin storage proteins of legume seeds. Phytochemistry, Oxford, v.15, p.3-24, 1976.

GALSTON, A.W. Regulatory systems in higher plants. American Scientist, New Haven, v.55, p.144-160, 1967.

GONÇALVES, C.H.R.P.; CURY, J.A.; CROCOMO, O.J. Isoenzimas na identificação e seleção de variedades de cana-de-açúcar (Saccharum spp.). In: CONGRESSO DA SOCIEDADE DE TÉCNICOS AÇUCAREIROS DO BRASIL, 2., 1981. Anais... p.329-340.

HART, G.E.; BHATIA, C.R. Acrylamide gel eletrophoresis of soluble leaf proteins and enzymes from Nicotiana species. Cannadian Journal of the Genetics and Cytology, Ottawa, v.9, p.367-374, 1967.

HEINZ, D.J.; GRACE, W.P. Mee. Plant differentiation from callus tissue of Saccharum species. Crop Science, Madison, v.9, p.346-348, 1969.

JOHNSON, B.L. Tetraploid wheats: seed eletrophoretic patterns of the Emmer and Timopheevi groups. Science, Washington, v.158, p.131-132, 1967.

JOHNSON, B.L. Protein electrophoretic profiles and the origin of the B genome of wheat. Proceedings of the National Academy of Science of the USA, Washington, v.69, p.1398-1402, 1972. 
JOHNSON, B.L.; HALL, O. Eletroforetic studies of species relationship in the Triticum. Acta Agriculture Scandinavica, Stockholm, v.16, p.222-224, 1966.

JOHNSON, B.L.; BARNHART, D.; HALL, O. Analysis of genome and species relationships in the polyploids wheats by protein eletrophoresis. American Journal of Botany, New York, v.54, p.1089-1093, 1967.

JOHNSON, B.L.; THEIN, M.M. Assessment of evolutionary affinities in Gossypium by protein electrophoresis. American Joumal of Botany, New York, v.57, p.1081-1092, 1970.

JOHNSON, C.B.; HOLLOWAY, B.R.; SMTH, H.; GRIERSON, D. Isoenzymes of acid phosphatase in germinating peas. Flanta, Berlin, v.116, p.1-10, 1973.

KELLEY, W.A.; ADAMS, R.P. Seasonal variations of isoenzimes in Juniperus scopulonom: systematic since. American Jourual of Botany, New York, v.64, n.9, p.1092-1096, 1977.

KRASNOOK, N.P.; MORGUNOVA, E.A.; BYKHTOYAROVA, E.T.; VISHNYAKOVA, I.A. Changes in activity and isoenzyme composition of cytoplasmic and mitochondrial dehidrogenases and cytochrome oxidase in reice seeds with different germinating capacites. Soviet Plant Fhysiology, Washington, v.26, n.1, p.64-70, 1979.

LARSEN, A.L. Isoenzymes and varietal identification. Seed World, Chicago, v.104, n.8, p.5-6, 1969.

LEE, J.W.; RONALDS, J.A. Effect of inironment on wheat gladin. Nature, London, v.213, p.844-846, 1967.

LOESCHCKE, V.; STEGMANN, H. Proteine der kartoffelknollen in abhangigkeit von sorte und virosen (polyacrylamideliktrophorese). Phytochemistry, Oxford, v.5, p.985-991, 1966.

LOOMIS, W.D. Overcoming problems of phenolics and quinones in the isolation of plant enzymes and ortanella. Methods in Enzymology, New York, v.31, p.528-544, 1974.

LOWRY, O.H.; ROSENBROGH, N.J.; FARR, A.L.; RANDALL, R.J. Protein measurement with the folinphenol reagent. Journal of Biological Chemistry, Baltimore, v.193, p.265-275, 1951.

MACKO, V.; HONOLD, G.R.; STAHMANN, M.A. Soluble proteins and multiple enzyme forms in early growth of wheat. Phytochemistry, Oxford, v.6, p.465-471, 1967.

MARKERT, C.L.; MOLLER, F. Multiple forms of enzymes: tissue, ontogenetic and species specific patterns. Proceeding of the National Academic Science of the USA, Wahington, v.45, p.753-763, 1959.
McCOWN, B.H.; HALL, T.C.; BECK, G.E. Piant leaf and stem proteins. II. Isozymes and environmental change. Plant Physiology, Rocksville, v.44, p.210-216, 1969.

NAGLE, N.E.; HAARD, N.F. Fracionation and characterization of peroxidase from ripe banana fruit. Journal of Food Science, Chicago, v.40, p.576-579, 1975.

OCKERSE, R.; SIEGEL, B.Z.; GALSON, A.W. Hormone induced repression of a peroxidase isozyme in plant tissue. Science, Washington, v.151, p.452-453, 1966 .

PIERCE, L.C.; BREWBAKER, J.L. Applications of isozyme analysis in horticultural science. FortScience, St. Joseph, v.8, n.1, p.17-22, 1973.

SCANDALIOS, J.G. Isoenzymes in development and differentiation. Annual Review of Plant Physiology, Stanford, v.25, p.255-258, 1974.

SCHAWARTZ, D. Genetic studies on mutant enzymes in maize: synthesis of hybrid enzymes by geterozygotes. Proceeding of the National Academic Science of the USA, Washington, v.46, p.1210-1215, 1960.

SHANONN, M.L. Plant isoenzymes. Annual Review Plant Physiology, Stanford, v.19, p.187-210, 1968.

SIEGEL, B.Z.; GALSTON, A.W. The isoperoxidase of Pisum sattrum. Plant Physiology, Rockville, v.42, p.221-226, 1967.

STODDART, J.L. Sequential changes in amylase isozyme during grain maturation in barley. Planta, Berlin, v.97, p.70-82, 1971.

THOM, M.; MARETZKI, A. Peroxidase and esterase isozymes in Hawaiian sugarcane. Hawaiian Planter's Record, Honolulu, v.58, n.6, p.81-94, 1970.

THURMAN, D.A.; PALIN, C.; LAYCOCK, M.V. Isoenzymatic nature of L-glutamic dehydrogenase of higher plants. Nature, London, v.207, n.4993, p.193-194, 1965.

TSENG-SHENG, G.L. Proteínas de reserva de feijăo (Phaseolus vulgaris). São Paulo, 1978. 125p. Dissertaç̃̃o (Mestrado) - Instituto de Química, Universidade de Sta Paulo.

WALDRON, J.C.; GLASZIOU, K.T. Isoenzymes as a method of varietal identificationin sugarcane. In: INTERNATIONAL CONGRESS OF THE SOCIETY OF SUGARCANE TECHNOLOGISTS, 14., 1972. New Orleans, p.249-259.

Recebido para publicação em 13.12 .93

Aceito para publicação em 06.04.94 